DOI: $10.36910 / 6775-2524-0560-2020-38-11$

УДК 004.932

Міскевич Оксана Іванівна, асистент

https://orcid.org/0000-0002-5009-2391

Войтович Ілля Вікторович, студент

Луцький національний технічний університет

\title{
ФОРМАТИ ЗОБРАЖЕНЬ ТА ДОЦІЛЬНІСТЬ ЇХ ВИКОРИСТАННЯ В СУЧАСНОМУ СВІТІ
}

Міскевич О.І., Войтович І.В. Формати зображень та доцільність їх використання в сучасному світі. В статті розповідається про основні формати зображень, растр та векторну графіку, різницю між ними, технології їх використання та цілі їх застосування.

Ключові слова: растр, вектор, RGB кодування кольорів, JPEG, JPEG2000, JPEG-XR, PNG, WEBP, CDR, AI, EPS, SVG.

Мискевич О. И., Войтович И.В. Форматы изображений и целесообразность их использования в современном мире. Статья рассказывает об основных форматах изображений, растр и векторную графику, разницу между ними, технологии их использования и цели их применения. SVG.

Ключевые слова: растр, вектор, RGB кодирование цветов, JPEG, JPEG2000, JPEG-XR, PNG, WEBP, CDR, AI, EPS,

Miskevych O., Ilya Voytovich. Image formats and the appropriateness of their use in the modern World. The article tells about the main image formats, raster and vector graphics, the difference between them, the technology of their use and the purpose of their application.

Keywords: raster, vector, RGB color coding, JPEG, JPEG2000, JPEG-XR, PNG, WEBP, CDR, AI, EPS, SVG.

Постановка задачі. Розглянемо принципи кодування зображень, правильне застосування їх в цифровому світі, різницю між основними форматами зображень та новинки на які варто звернути увагу. Наведемо приклади кодування різних форматів, порівняємо їх кінцеві показники послідовність обробки (рис. 1).

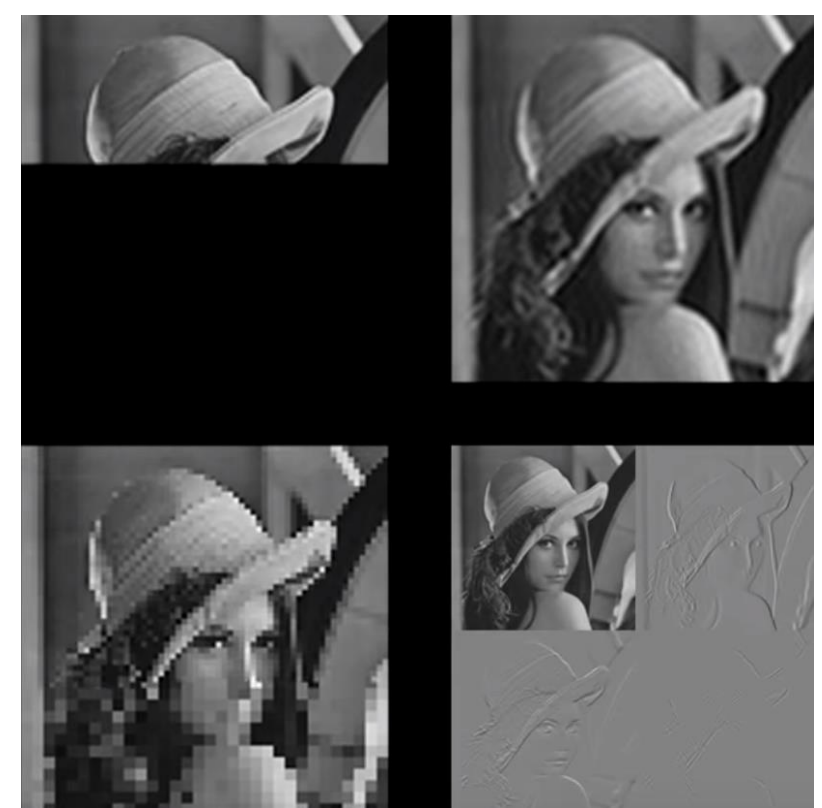

Рисунок 1 - Послідовність обробки Baseline JPEG, Progressive JPEG, дискретним косинусним перетворенням, вейвлет-перетворенням

Метою даного дослідження с отримання кінцевих показників зображень і приклад як можна використати ці показники в різних середовищах.

Основна частина. Растрові формати включають в себе сітку пікселів, тобто інтерпретований переглядачем код. Відповідно мета формату - показати набором символів будь-яке зображення (рис. 2). Формат JPEG стискає картинку з втратою якості. Вихідне зображення розбивається і групується на квадрати 8x8 пікселів. Головна мета формату JPEG - підібрати такий рівень якості, щоб вага зображення була невелика і якість картинки була адекватною (рис. 3). Вага зображення включаючи стиснення в

(C) Міскевич O.I., Войтович I.B. 
форматі JPEG залежить від кількості кольорів, роздільної здатності і розміру. Отже основні характеристики цього формату:

- найпопулярніший формат;

- малий розмір файлів;

- д добре стискає фото, але псує чіткі лінії;

- не має прозорості;

- не більш ніж 8 біт на канал.

\begin{tabular}{|c|c|c|c|}
\hline \multicolumn{4}{|c|}{ Шістнадцятковий код: } \\
\hline \multicolumn{4}{|c|}{211813 321F15 613C1C 75411E } \\
\hline \multicolumn{4}{|c|}{$6142296 F 5949938479$ 3E4545 } \\
\hline \multicolumn{4}{|c|}{ 7D5C25 6A6E67 706769362624} \\
\hline \multicolumn{4}{|c|}{ 4B2E10 4B2D11 $312120 \quad 3 B 2316$} \\
\hline \multicolumn{4}{|c|}{ Переводим в десятковий код: } \\
\hline R: 033 & R: 050 & R: 097 & R: 117 \\
\hline G: 024 & G: 031 & G: 060 & G: 065 \\
\hline B: 019 & B: 021 & B: 028 & B: 030 \\
\hline R: 097 & R: 111 & R: 147 & R: 062 \\
\hline G: 066 & G: 089 & G: 132 & G: 069 \\
\hline B: 041 & B: 073 & B: 121 & B: 069 \\
\hline R: 125 & $\mathrm{R}: 106$ & R: 112 & R: 054 \\
\hline G: 092 & G: 110 & G: 103 & G: 038 \\
\hline B: 037 & B: 103 & B: 105 & B: 036 \\
\hline R: 075 & $\mathrm{R}: 075$ & R: 049 & R: 059 \\
\hline G: 046 & G: 045 & G: 033 & G: 035 \\
\hline B: 016 & B: 017 & B: 032 & B: 022 \\
\hline
\end{tabular}

Рисунок 2 - Приближена ділянка фотографії, кожен піксель якої - окремий код кольору

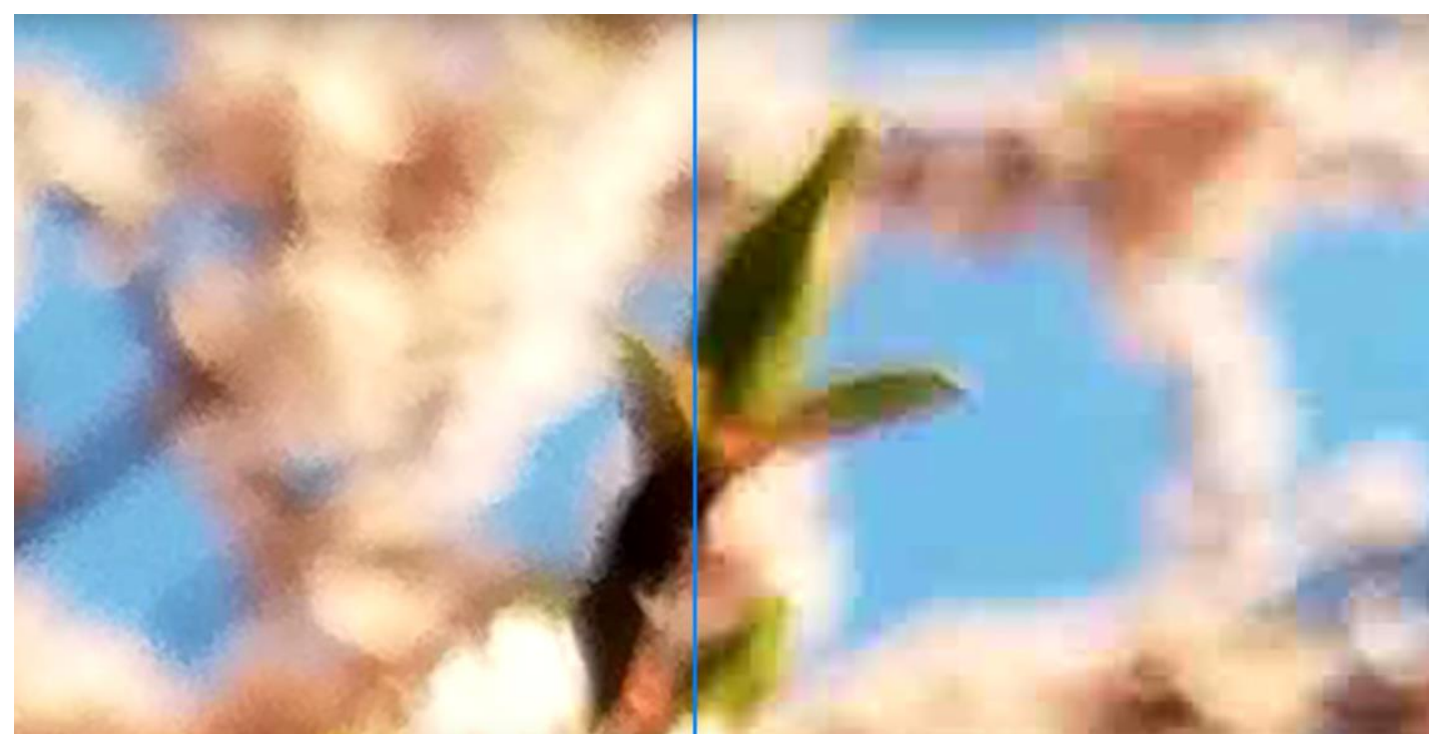

Рисунок 3 - Ліва частина зображення - до стиснення форматом JPEG, права частина - після

Отже замість популярного формату JPEG ми можемо використати менш відомий його нащадок JPEG2000. Цей формат володіє всіма характеристиками свого попередника, але зі зміненим алгоритмом обробки. Замість дискретного косинусного перетворення, використовує вейвлет-перетворення. Зображення зменшується в два рази, для нього знаходяться різниці по вертикалі, по горизонталі та усереднене значення по діагоналі. Процес повторюється декілька разів. (рис. 4). Плюси використання:

() Міскевич О.І., Войтович І.В. 
- відсутня блочність;

- прогресивне завантаження;

- мініатюра вихідного зображення присутня в самому файлі;

- підтримка 16-бітного кольору.

Оновлена версія JPEG2000 має назву JPEG-XR і також відрізняється способом кодування зображення. Замість вейвлет-перетворення використовується кодування блоками $4 \mathrm{x} 4$ пікселі і другим рівнем для макро-блоку $16 x 16$. Підтримує різні опції субдискретизації. Проте цей формат рідко використовується i не підтримується багатьма браузерами та пристроями.

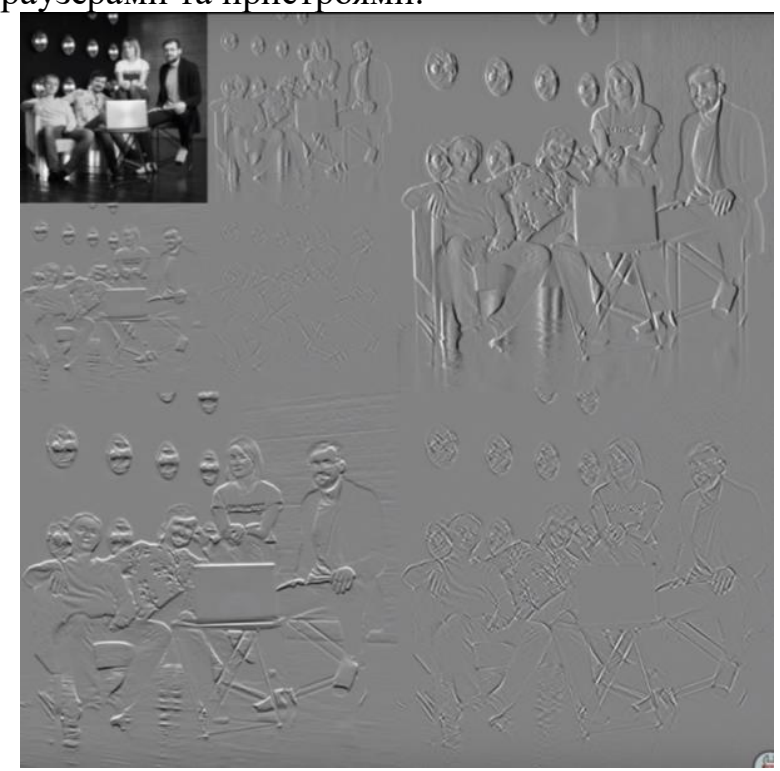

Рисунок 4 - Вейвлет-перетворення

Формат PNG є форматом стиснення без втрати якості і дозволяє зберігати зображення, в яких потрібна особлива точність. Має дві варіації: PNG8 та PNG24. Перший може мати лише 256 кольорів, а PNG24 використовує більше 16 мільйонів кольорів. Головна особливість формату PNG - підтримка альфа-прозорості, тобто кожному пікселю окремо можна задати свою степінь прозорості (рис. 5). Однак за рахунок стиснення без втрат, зображення цього формату мають велику вагу. Також має функцію дописування додаткових блоків. Це дало можливість реалізувати анімацію без втрати зворотньої сумісності.

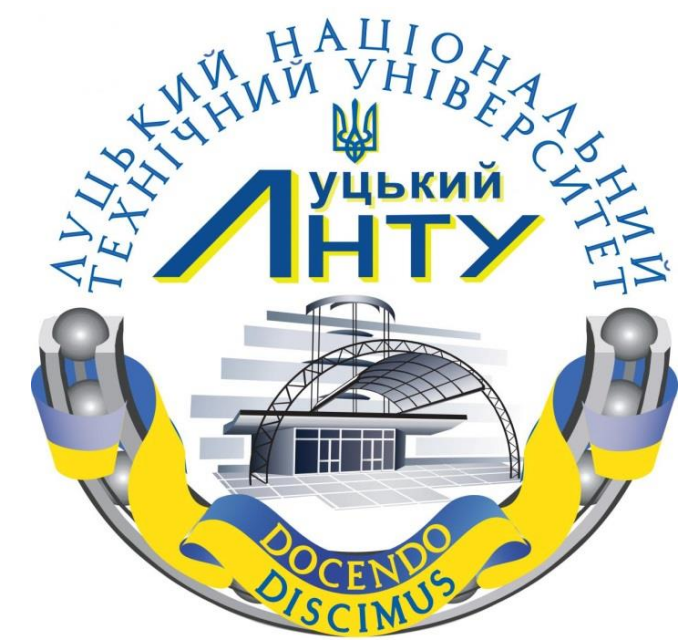

Рисунок 5 - Логотип університету з прозорим фоном

WEBP - не $\epsilon$ окремою розробкою. Його алгоритми використовують алгоритми відео-кодеків для стиснення ключових кадрів. В ньому відбувається перетворення 3 RGB в YUV (рис. 6) і також застосовується дискретне косинусне перетворення. На відміну від формату JPEG, блоки можуть розбиватись як на 4x4 так і на 16x16 пікселів. Алгоритм визначає де і яка буде точність, орієнтуючись на (c) Міскевич O.I., Войтович I.B. 
деталізацію ділянок (рис. 7). Найцікавіше - це кодування частини зображення схожим на JPEG способом і з передбаченням на наступні блоки, опираючись на вже відомі. У випадку коли передбачення можна успішно здійснити з малою кількістю помилок, підраховується помилка передбачення й яка зберігається замість блоку.

Також за допомогою формату WEBP можна стискати зображення з втратами, але без втрат каналу прозорості. Такого не вміє ні один з популярних форматів.

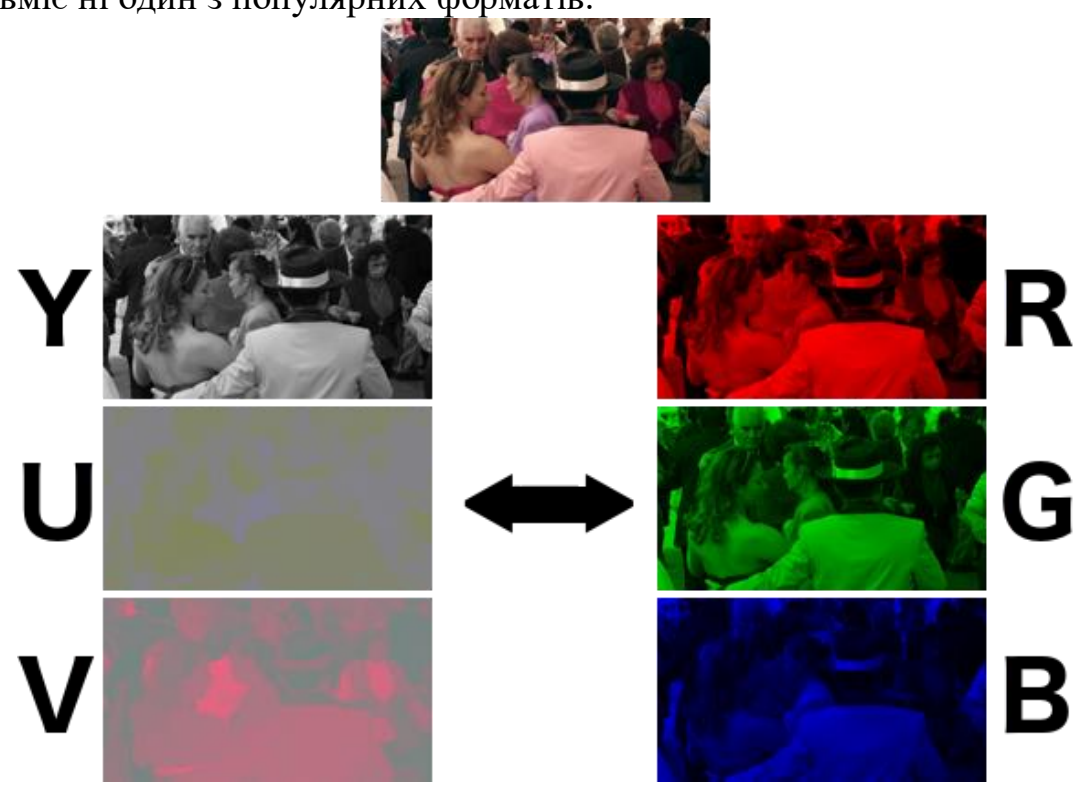

Рисунок 6 - Перетворення з RGB в YUV, і навпаки

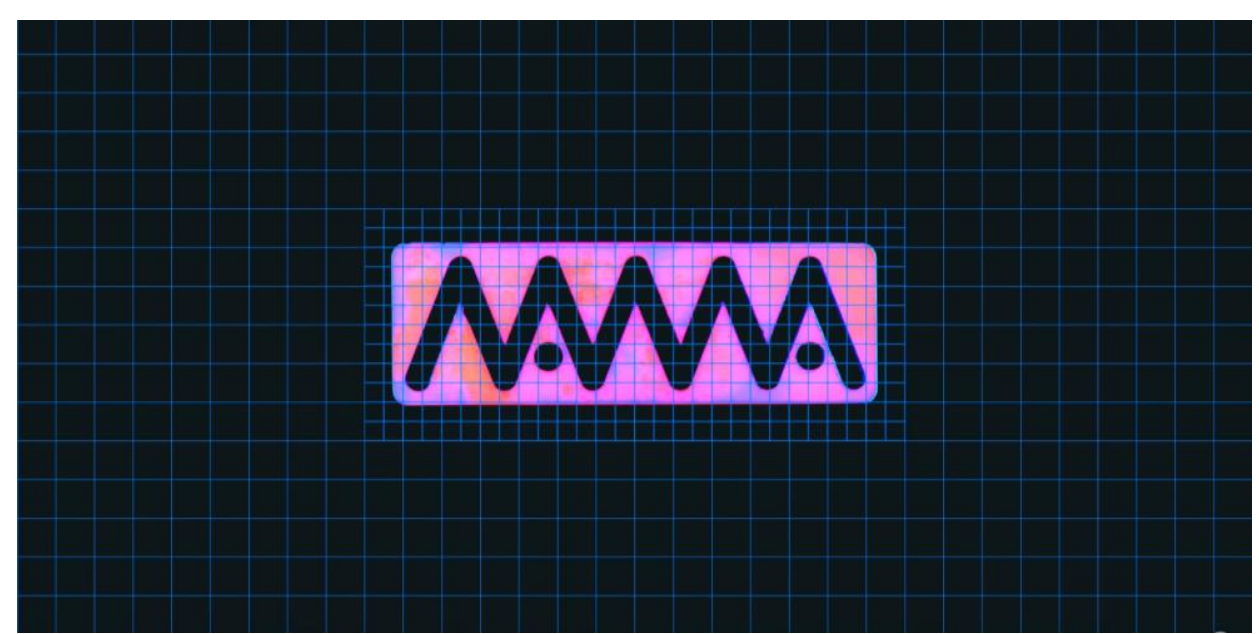

Рисунок 7 - Визначення алгоритмом ділянок з більшою деталізацією із застосуванням блоків $16 \times 16$ пікселів

Основу векторних форматів становлять математичні формули, геометричні представлення фігур, примітиви. Примітиви складають фігури, фігури можуть мати заливку, обведення тощо. Векторна графіка містить в собі інструкції комп'ютеру як щось намалювати (точки на певних координатах, 3’єднання цих точок певною кривою, код кольору, товщина лінії і т.д.). 

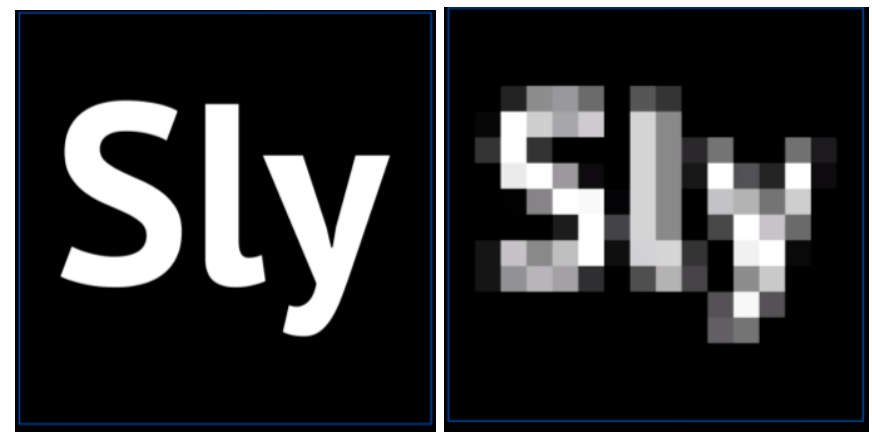

Рисунок 8 - Ліва частина - логотип в векторному форматі, права - після растеризації

На фінальному етапі такого малювання при виведенні на екран доводиться перетворювати ідеальну математичну модель в пікселі. Саме це називається растеризацією (рис. 8). Для прикладу до векторної графіки відносяться шрифти, іконки, логотипи, ілюстрації.

Всі векторні формати схожі і різниця між ними лише в редакторі, в якому створюється вектор. Кожен редактор має свої специфічні особливості. Серед відомих форматів можна виділити CDR (редактор CorelDraw), AI (Adobe Illustrator), EPS (ранні версії Adobe Illustrator, проте часто використовується 3 огляду на його широку сумісність), SVG (відкритий формат, який розуміють усі браузери). Існує не один десяток векторних форматів, але сенс кожного один - описати математично те, що потрібно намалювати.

\section{Висновки}

Отже, формат зображень JPEG є дуже гнучкий і в залежності від того, наскільки якісним має бути картинка залежить вага зображення. Для відображення найкраще застосовувати принцип перетворення Progressive JPEG або дискретне косинусне перетворення. Формат дуже поширений і підтримується у всіх сферах використання. Застосовується для фотографій.

Для заміни всім відомого JPEG, в сучасному світі показує себе формат JPEG2000. Використовує більш досконалий алгоритм вейвлет-перетворення, що дозволяє стиснути картинку без втрат. Не гірший, ніж його попередник, проте менш поширений і підтримується лише відомими браузерами та операційними системами.

PNG формат призначений більше для роботи між редакторами або для відображення логотипів, невеликих зображень. Часто застосовується в Web-павутині. Має повноцінну прозорість через альфаканал, стискає картинки без втрат, ідеальний для графіки. Не призначений для публікації фотографій.

WEBP - відносно свіжий формат, який представила компанія Google. На третину краще стискає, ніж формат JPEG, підтримує прозорість при стисненні з втратами, анімацію і при необхідності може стискати зображення без втрат. Тобто поєднує сильні сторони JPEG та PNG. Формат не підтримується багатьма пристроями та операційними системами.

Векторні формати відрізняються від растру. Мета будь-якого векторного формату - математично описати те, що має намалювати браузер або програма. Комп’ютер може нескінченно масштабувати картинку до етапу растеризації без втрат якості. Векторна графіка застосовується для логотипів, іконок, шрифтів, ілюстрацій. Всі векторні формати схожі і відрізняються лише редакторами. Найпопулярніший формат - SVG, який є відкритим браузерним форматом і підтримується будь-якими OC.

\footnotetext{
1. Форматы изображений для Веба - Блог Академии - ${ }^{\text {СTML }}$ Academy. URL: https://htmlacademy.ru/blog/boost/graphics/image-formats (дата звернення: 20.02.2020).

2. William B. Pennebaker, Joan L. Mitchell JPEG: Still Image Data Compression Standard (Digital Multimedia Standards S) : монографія. USA, Springer, 1993. 5 с.

3. Графічні формати - Вікі ЦДПУ. URL: https://wiki.cuspu.edu.ua/index.php/Графічні_формати

4. Форматы изображений, часть 1 - SlyLama. URL: https://www.youtube.com/watch?v=P1K0ZNGczsk (дата звернення: 13.09.2019).

5. Каганюк О.К., Поліщук Т.О., Міскевич О.І. Аналіз способів контролю розділу кордону «порода - вугілля» для створення систем автоматичного управління вугільно видобувними комбайнами. / Комп'ютерно-інтегровані технології: освіта, наука, виробництво. №36., ст. 29-34, 2019p.

6. Гринюк С.В., Бортник К.Я., Міскевич О.І., Паливода Д.І. Огляд інструментальних засобів для створення ігор під ОС Android. / Комп'ютерно-інтегровані технології: освіта, наука, виробництво. №35., ст. 124-128, 2019p.
} 
7. Міскевич О.І., Сичов Д.І., Христинець А.О. Про модернізацію локально-обчислювальної мережі на ПрАТ "Волиньобленерго" на основі GRE-tunnel з використанням шифрування IPSec. / Комп'ютерно-інтегровані технології: освіта, наука, виробництво. №31., ст. 100-103, 2018p.

\section{Reference}

1. Image formats for the Web - Academy Blog - HTML Academy. URL: https://htmlacademy.ru/blog/boost/graphics/image-formats (accessed: 02/20/2020).

2. William B. Pennebaker, Joan L. Mitchell JPEG: Still Image Data Compression Standard (Digital Multimedia Standards S):

Monograph. USA, Springer, 1993. 5 p.

3. Graphic Formats - CDU Wiki. URL: https://wiki.cuspu.edu.ua/index.php/Graphic_formats

4. Image formats, part 1 - SlyLama. URL: https://www.youtube.com/watch?v=P1K0ZNGczsk (accessed 13/09/2019).

5. Kaganyuk O.K., Polishchuk T.O., Miskevych O.I. Analysis of methods of control of the section "border - coal" for creation of systems of automatic control of coal-mining combines. / Computer-integrated technologies: education, science, production. No. 36, Art. 29-34, 2019

6. S.V. Grynyuk, K.Ya. Bortnik, O.I. Miskevych, D.I. Palivoda An overview of tools for creating games on Android. / Computerintegrated technologies: education, science, production. No. 35, Art. 124-128, 2019.

7. Miskevych O.I., Sychev D.I., Khrystinets N.A. About modernization of the local area network on PJSC "Volynoblenergo" based on GRE-tunnel using IPSec encryption. / Computer-integrated technologies: education, science, production. №31., Art. 100-103, 2018 